\title{
Breve revisão histórica da política e educação venezuelanas no século XX
}

Júlia Mariano Pereira

Estudante de mestrado em Conhecimento e Inclusão Social na Faculdade de Educação da Universidade Federal de Minas Gerais (FaE/UFMG), Belo Horizonte, Brasil, e membro do Centro de Educação Popular e Pesquisas Econômicas e Sociais (CEPPES).

\section{Resumo}

Para entender as implicações da Revolução Bolivariana sobre a educação, esse texto visita 50 anos da história política e das políticas educacionais na Venezuela no período anterior à eleição de Hugo Rafael Chávez Frías à presidência. $O$ trabalho tenta romper com a dissociação entre o aspecto econômico (objetivo) e o político (subjetivo) nas análises sobre o processo de transformações que a Venezuela atravessa, contribuindo com uma compreensão marxista da realidade venezuelana atual; ou seja, compreensão através do materialismo histórico-dialético.

Palavras-chave: Venezuela, Revolução Bolivariana, Educação, História Latino-americana, Políticas educacionais

\section{Resumen}

Para compreender las implicaciones de la Revolución Bolivariana sobre la educación, este texto visita 50 años de historia política y políticas educacionales en Venezuela en el período que antecede la elección de Hugo Rafael Chávez Frías a presidente. El trabajo intenta romper la disociación entre el aspecto económico (objetivo) y el político (subjetivo) en las análises sobre el proceso de transformaciones que Venezuela atraviesa para contribuir con una compreensión marxista de la realidad venezolana actual; en otras palabras, compreensión a través del materialismo histórico-dialéctico.

Palabras claves: Venezuela, Revolución Bolivariana, Educación, Historia latinoamericana, Políticas educaionales

\section{Abstract}

To understand the implications that the Bolivarian Revolution has on education, this article visits 50 years of political history and of educational policies in Venezuela in the period prior to the presidential election of Hugo Rafael Chávez Frías. It attempts to break the dissociation between the economic (objective) and political (subjective) aspects in the analyses of the transformation process Venezuela is experiencing while contributing to a Marxist comprehension of Venezuela's current reality; in other words, a comprehension through historical-dialectical materialism.

Keywords: Venezuela, Bolivarian Revolution, Education, Latin American History, Educational Politicies 

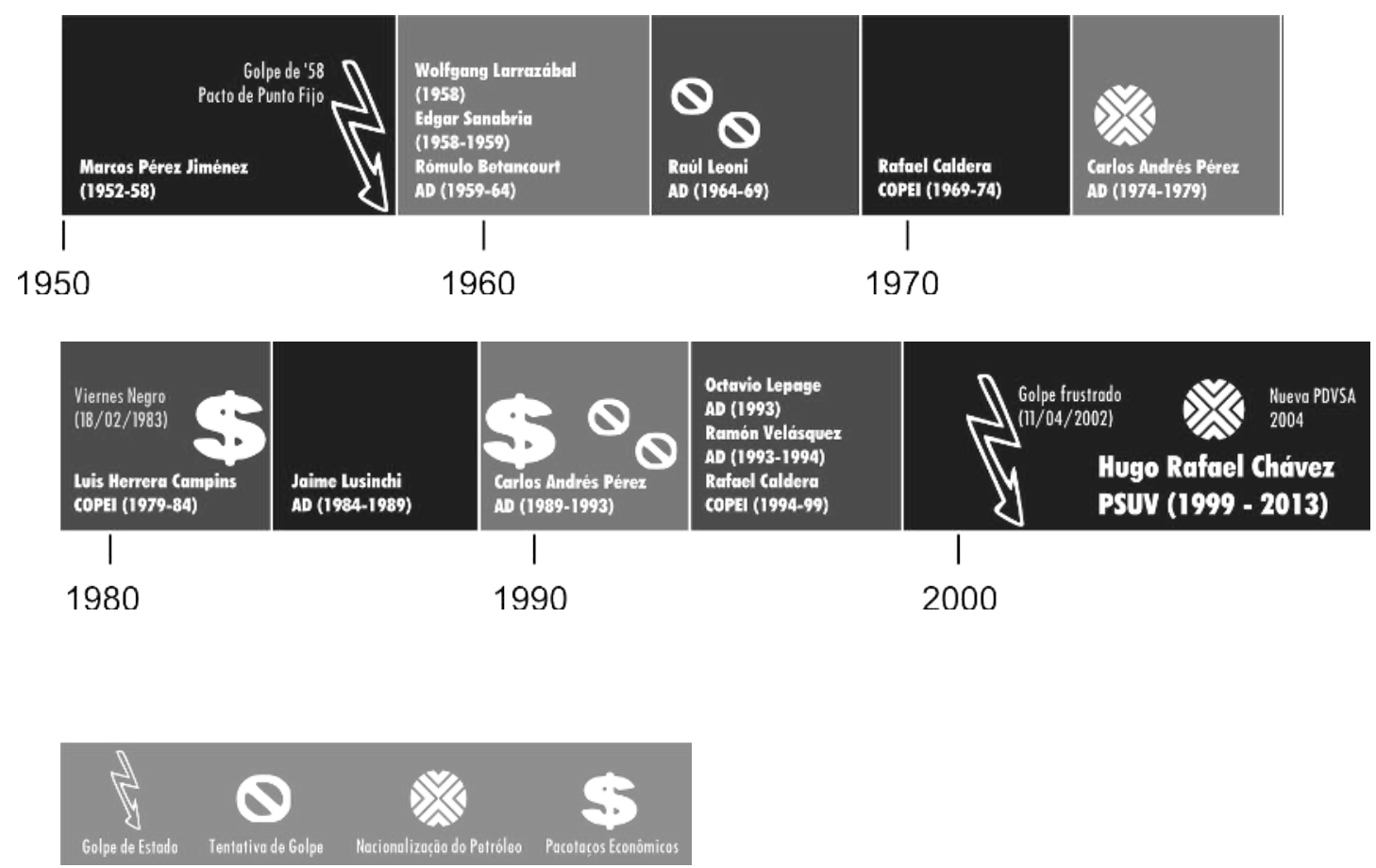

Figura 1: Presidentes da Venezuela entre 1952 e 2002 (Fonte: WIKIPEDIA, passim).

\section{Educação na Venezuela hoje}

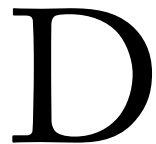
e acordo com o Instituto de Estatísticas da UNESCO (UIS. UNESCO Institute of Statistics) a educação básica na Venezuela em termos gerais está hoje próxima à média regional. As cifras podem parecer um tanto tímidas para um país que se denomina em "Revolução Rumo ao Socialismo", considerando que, como América Latina, ainda ostentamos níveis significativamente inferiores às economias desenvolvidas da Europa. Porém, em uma análise como essa, a natureza dos números guarda certa semelhança à de uma bailarina russa do balé clássico: pálida e magricela, sua beleza se revela em seu movimento no tempo.

\section{Atualidade: Números em movimento}

A taxa bruta de matrícula (TBM) na educação pré-escolar foi de 74\% (média regional 73\%) em 2011, um incremento de cerca de 30\% em comparação com os $45 \%$ de 1999. A TBM na educação primária cresceu de $85 \%$ em 1999 a $102 \%$ em 2011 (m.r. 112\%) e na secundária avançou de 48\% em 1999 aos atuais 83\% (90\%) (UIS. UNESCO Institute of Statistics).A evasão caiu de 15\% em 2000 (13,04\%) a menos de 5\% em 2010 (8,31\%) (UNESCO. The State of Education in Latin America and the Caribbean: Towards a Quality Education for All-2015. OREALC/UNESCO, 2013, pp. 60).

Das crianças que entram na educação primária, $96 \%$ chegam à sua conclusão no sexto grau, com um índice de repetência de 4\%. A taxa de progressão entre primária 
e secundária em 2011 foi de aproximadamente 98\% (93,5\%), uma das mais altas do continente (UIS. UNESCO Institute of Statistics).

A Venezuela se destaca também como um dos países com menor desigualdade no acesso ao ensino. A diferença de acesso entre os $20 \%$ mais ricos do país e os $20 \%$ mais pobres é inferior a 5\%, cifra que em alguns países da América Latina pode chegar a mais de 20\% (UNESCO. The State of Education in Latin America and the Caribbean: Towards a Quality Education for All-2015. OREALC/UNESCO, 2013, p. 60).

Segundo relatório da UNESCO sobre o estado da educação na América Latina e Caribe em 2013, junto à Bolívia e à Argentina, a Venezuela conseguiu reduzir seu nível de pobreza a quase metade desde 2000 (UNESCO. The State of Education in Latin America and the Caribbean: Towards a Quality Education for All-2015. OREALC/ UNESCO, Santiago, Chile: 2013. Pg. 60), indicador que a UNESCO considera a "variável contextual mais relevante para o acompanhamento da educação"(UNESCO. The State of Education in Latin America and the Caribbean: Towards a Quality Education for All-2015. OREALC/UNESCO, Santiago, Chile: 2013, p. 60).

$\mathrm{O}$ mesmo relatório aponta à Venezuela e à Costa Rica como os países da região com a mais destacada redução na evasão escolar. $\mathrm{O}$ relatório destaca ainda o aumento em mais de $20 \%$ na cobertura de educação secundária venezuelana e estima que, desde 2000, o país progrediu 50\% rumo ao Objetivo do Milênio de Educação Primária Universal (UNESCO. The State of Education in Latin America and the Caribbean: Towards a Quality Education for All-2015. OREALC/UNESCO, Santiago, Chile, 2013, p. 60).

Sobre a educação superior, o UIS estima que a TBM em 2000 era de cerca de 38\%, atingindo em 2011 78\%, inferior no continente apenas a Cuba (95\%) (SEGRERA, 2013). Segundo o professor venezuelano Pedro Rivas, 93\% dos estudantes que entraram à educação universitária em 2000 vinham de escolas particulares, sendo que apenas 117 estudantes das classes D e E entraram à Universidad Central de Venezuela, a principal instituição pública do país, e apenas 10 entraram à Simon Bolívar, pública e de 'excelência acadêmica' reconhecida internacionalmente (RIVAS, 2007).

O grande feito e uma das primeiras conquistas na educação foi erradicar o analfabetismo em 2005. Apesar de um país ser considerado livre de analfabetismo pela UNESCO com 4\% de analfabetos, o índice venezuelano chegou a 0,10\% (ZUCK, 2009, p. 4).

Ainda que esses números possam trazer muito mais otimismo para a Venezuela, Oder José dos Santos aponta que

A educação e a escola constituem uma das condiçôes gerais de produção e reprodução da força de trabalho. [...] A compreensão desses processos implica considerar a dinâmica dos diferentes padrões de acumulação de capital que presidem o desenvolvimento econômico. Tais padrões determinam os diferentes objetivos a serem alcançados no âmbito da educação (SANTOS, 2004, p. 79).

Essa perspectiva nos ajudará a entender de maneira mais profunda porque e para onde os números e concepções de educação se movem no tempo. Partimos, assim, a acompanhar a história da Venezuela para compreender, em seu movimento no tempo, como o país e sua educação chegaram às condições que se encontravam no ano de 1999. 


\section{Desenvolvimento Econômico da Venezuela}

Inicialmente, a economia venezuelana foi como uma típica colônia ameríndia, onde

O capital comercial desta etapa, ao enfrentar uma forma produtiva determinada, propóe como único fim a extração da maior quantidade possivel de trabalho excedente. [...] essa 'fome de trabalho excedente' esteve acompanhada no geral pela imposição das relaçôes marcadas fortemente de aspectos servis [não capitalistas], onde o elemento distintivo será o uso da força, ou seja, da coação extra-econômica. (ASSADOURLAN e outros, 1986, p. 11)1 (itálicos do autor).

Porém, os colonizadores não encontraram o El Dorado prometido, mas ao contrário, um modo de produção muito menos desenvolvido e muito menos interessante quando comparado às riquezas do império Tahuantinsuyo (Inca) e às minas de Potosí: o nome "pequena Veneza" é devido às palafitas das comunidades originárias. A Venezuela só ganhou destaque como colônia e entrou no mercado capitalista internacional com a exportação de cacau na metade do século XVII, intermediada pela metrópole espanhola. Em relação à importância desse rubro, o historiador Brito Figueroa ilustra "o cacau, apesar da sua cor escura, adquiriu brilho de ouro, como hoje tem o petróleo, que é ainda mais escuro" (FIGUEROA, 1975, pp.101-102).

A insustentabilidade das relações de produção no modelo colonial fez com que uma fração da classe dominante na época, liderada por Simón Bolívar, travasse a luta pela independência contra uma aliança heterogênea entre as classes dominantes da metrópole espanhola e a nascente classe dominante do continente americano.

Forjadas a ferro e fogo, as relações de produção coloniais se mantiveram em certa medida na nascente Gran Colombia, ainda que a independência política representasse uma situação qualitativamente distinta à anterior. Forjadas também as raízes do povo venezuelano: em 1800 a população era composta por 20,3\% brancos, $8,4 \%$ indígenas e 61,3\% pardos e negros (FIGUEROA; 1975). Segundo o Censo de 2011(MASTRONALDI e BLANCO, 2012), o primeiro na história do país a incluir perguntas sobre autorreconhecimento étnico, $42,2 \%$ dos venezuelanos se consideram brancos, 2,7\% indígenas, 3.5\% negros ou afrodescendentes e $49,9 \%$ se dizem morenos. A divisão da Grande Pátria, frustração gritante do sonho de Bolívar, representou não apenas a configuração de Estados-nações mais fracos com economias mais dependentes, mas também a fundação da própria Venezuela como uma "nação recortada em senhorios locais, cuja maneira de se comunicar radicava na guerra civil permanente" (RANGEL, 1971, p.11).

Inaugurando o século XX, o ditador Juan Vicente Gómez dedicou sua estadia na presidência (1908 a 1935) - ocupando o cargo diretamente ou através de presidentes provisórios sobre os quais exercia poder - a limpar esse cenário de perpétuas guerras civis, estruturando ao seu redor um Estado-nação moderno, requisito imprescindível para o capitalismo petrolífero que viria a se desenvolver no século XXI. Exterminando os tradicionais caudilhos onde necessário e mantendo certas alianças regionais onde conveniente, Gomez foi livrando o território nacional dos "feudos herméticos que impunham um obstáculo insuperável ao desenvolvimento das forças produtivas" (1971, p.16). Assim, desenvolveu-se a infraestrutura física que permitiu, por sua vez,

1 Esta tradução e as que se seguem foram feitas pela autora do artigo. 
Tabela 1

Crescimento da matrícula estudantil da educação primária por período governamental (1951-2001)

\begin{tabular}{|c|c|c|c|c|c|c|}
\hline & \multirow{2}{*}{\multicolumn{3}{|c|}{ Período governamental }} & \multicolumn{3}{|c|}{ Matrícula } \\
\hline & & & & \multirow{2}{*}{$\begin{array}{r}\text { Pública } \\
31,1 \%\end{array}$} & \multirow{2}{*}{$\begin{array}{r}\text { Privada } \\
98,4 \%\end{array}$} & \multirow{2}{*}{$\begin{array}{l}\text { Total } \\
39,0 \%\end{array}$} \\
\hline 1 & Marcos Pérez Jimenez (m & ilitar) & $1952-1958$ & & & \\
\hline 2 & Junta de Gobierno & & $1958-1959$ & $27,8 \%$ & $-1,7 \%$ & $23,2 \%$ \\
\hline 3 & Rómulo Betancourt ( $A D)$ & & $1959-1964$ & $53,2 \%$ & $29,9 \%$ & $49,9 \%$ \\
\hline 4 & Raúl Leoni $(A D)$ & & 1964-1969 & $19,2 \%$ & $19,7 \%$ & $19,3 \%$ \\
\hline 5 & Rafael Caldera (COPEI) & & $1969-1974$ & $21,2 \%$ & $7,9 \%$ & $19,6 \%$ \\
\hline 6 & Carlos Andrés Pérez $(A D)$ & & 1974-1979 & $24,0 \%$ & $19,9 \%$ & $23,6 \%$ \\
\hline 7 & Luis Herrera Campins ( $C$ & $O P E I$ & 1979-1984 & $10,5 \%$ & $15,2 \%$ & $11,0 \%$ \\
\hline 8 & Jaime Lusinchi $(A D)$ & & 1984-1989 & $11,9 \%$ & $15,6 \%$ & $12,3 \%$ \\
\hline 9 & Carlos Andrés Pérez $(A D)$ & & 1989-1993 & $5,5 \%$ & $50,0 \%$ & $10,7 \%$ \\
\hline 10 & Octavio Lepage $(A D)$ - & Ramón José Velásquez ( $A D)$ & 1993-1994 & $-2,0 \%$ & $5,0 \%$ & $-0,8 \%$ \\
\hline 11 & Rafael Caldera (COPEI) & & 1994-1999 & $2,5 \%$ & $-11,6 \%$ & $0,06 \%$ \\
\hline 12 & Hugo Chávez Frías (Pólo & Patriótico) & 1999-2001 & $8,0 \%$ & $-3,4 \%$ & $7,5 \%$ \\
\hline
\end{tabular}

Fonte: LUQUE, 2011, pg.83

o desenvolvimento comercial e financeiro do país. O moderno estado do começo do século XX se sentava sobre três bases: uma burocracia fiel e bem armada, indicada pelo governo central; uma nova estrutura fiscal que centralizava parte da riqueza da nação; e o Exército, cuja união, identidade e fidelidade foram forjadas sob o regime ditatorial gomecista (RANGEL 1971, passim).

Somente a partir desse momento, com um Estado-nação moderno, pôde ser concebida uma educação pública e nacional. Foi justamente aqui que foi concedida à Igreja Católica uma destacada presença na educação até então laica que perdura até o final do século, pois, “o gomecismo começará a conceder à Igreja muitas aspirações que, atados a seu ideário liberal, os caudilhos do século XIX lhe negaram”(RANGEL, 1971, p. 43).

Depois da descoberta do petróleo, poucos setores da economia receberam a atenção e o investimento das classes dominantes que estão até hoje vinculadas à atividade extrativista, principalmente de petróleo e ferro, e à exportação/importação de bens, mantendo vínculos econômicos, políticos, afetivos e militares com Miami. Durante sua história, deram prioridade a esses vínculos em detrimento do desenvolvimento nacional, construindo uma forte identidade de classe com os centros imperialistas e um rechaço a tudo que fosse venezuelano. A presença estadunidense é declarada e forte inclusive depois da nacionalização do petróleo em 1975, a ponto dos altos cargos do país caribenho nunca terem sido ocupados por pessoas que não caíssem nas graças de Washington (RANGEL, 1971, p. 28).

As primeiras eleições diretas do século XX ocorreram em 1947, pouco depois do Golpe de Estado de Rómulo Betancourt em 1945 e pouco antes do Golpe de Estado de 1948. Entre vai-e-vens, juntas militares e eleições indiretas, o ditador Marcos Pérez Jimenez é tirado do poder em 1958 por outro Golpe de Estado, agora com participação civil. Foi então selado o famoso Pacto de Punto Fijo, acordo que deu início ao regime bipartidário entre a social-democracia (partido Acción Democrática) e a democracia-cristã (COPEI), pintada por alguns como fase de 'estabilidade política', mas que representa na verdade uma ditadura civil. Assim crescem e se desenvolvem 
as principais tendências econômicas citadas antes, agravadas pelo próprio desenvolvimento do capital internacional e do neoliberalismo, levando a Venezuela no final do século XX a índices altíssimos de pobreza apesar de ser o principal exportador de petróleo do continente.

Nota-se que os Golpes de Estado não são exceção na política do país, foram 12 tentativas ou golpes de fato entre 1835 e 2002, sete deles entre 1945 e 1992. Isso demonstra de certa forma o que o historiador Domingo Alberto Rangel aponta como outro legado do estado moderno fundado por Gomez: "nenhum regime venezuelano surgiu ou permaneceu na direção do país sem a anuência ou iniciativa das Forças Armadas." (RANGEL, 1971, p. 37).

Porém, nem toda insurgência foi apenas militar. Roberto López Sanchez afirma que a história venezuelana "está caracterizada pelas contínuas revoluções políticas nas quais um grupo insurgente de raízes populares derroca o previamente existente; assim aconteceu no processo independentista e continuou em 1848, 1863, 1870, 1899, 1945, 1958 e 1998," (LÓPEZ SÁNCHEZ, 2002, p. 2), o que implica que nenhum grupo econômico hegemônico tenha dominado a política nacional por mais de 50 anos.

A luta de classes tem implicações sobre todos os setores da sociedade incluindo a educação. É possível ver como as tendências educacionais acompanharam os diversos e contraditórios momentos políticos do país através de uma breve revisão histórica das políticas educacionais na Venezuela.

\section{Implicações sobre a educação}

A pedagoga e pesquisadora venezuelana Yolanda Ramírez afirma que, a experiência das reformas educacionais mostrou "o divórcio entre o discurso plasmado nos fundamentos dos planos de estudo e o desenho levantado sobre eles" (LÓPEZ SÁNCHEZ, 2002, p. 534). Porém pode-se observar como as políticas educacionais avançavam e retrocediam de acordo com os interesses políticos do governo de turno que, por sua vez, obedecia à dinâmica econômica e política internacional na qual a nação caribenha se via inserida.

\section{Os últimos anos do Gomecismo sem Gomez}

Em análise das diferentes reformas educacionais entre 1951 e 2001, Ramírez retrocede um pouco no tempo e mostra como o país teve muita influência da Escola Nova de John Dewey e Decroly em meados da década de 1930, com a pedagogia de projetos e certa democracia escolar para escolher ditos projetos na perspectiva de "aprender fazendo". Ao olhar o panorama político da Venezuela naquele momento, veremos que o povo, majoritariamente rural e 80\% analfabeto (LUQUE, 1951-2001, pp. 666-736 e p. 679), despertava para uma “abertura democrática” depois da saída de Gomez do poder: era necessário construir um novo país. Luis Prieto Figueroa, um dos fundadores da Sociedad Venezolana de Maestros de Instrucción Primaria (SVMIP), primeira organização da categoria, naquele momento se dedicou a divulgar as teses do magistério sobre a Escola Nova. Eleito ao senado, majoritariamente gomecista, Figueroa tentou aprovar a primeira Ley Orgánica de Educación, que caracterizava a instrução laica, pública, obrigatória de 1 a 16 anos de idade, com garantia de comida e moradia a todos. A proposta foi derrotada pela direita, com quadros formados 
diretamente pelo vaticano como Rafael Caldera (futuro presidente por COPEI), que lançou uma ampla campanha contra o monopólio do estado sobre a educação, contra a educação laica e contra o socialismo/comunismo (LUQUE, 2011, pp. 680-682).

Tanto o governo de Lopez Contreras quanto o de seu sucessor Medina representaram democracias tuteladas que permitiam certos debates e avanços na educação, mas sem progredir muito, dedicando seus principais esforços a estruturar o país para eleições diretas. Quando essa bandeira eleitoral se viu ameaçada no final do mandato de Medina, foi realizado outro golpe de estado em 1945 com apoio da esquerda, que levou Rómulo Betancourt à presidência e Figueroa à Junta Revolucionaria de Gobierno (JRG).

\section{O Golpe de Acción Democrática (1945)}

O programa para a educação depois do golpe de $A D$ incluiria “inspeção escolar, alfabetização de adultos, impulso à escola rural, educação para saúde e [educação] especial, aumento de salário e proteção social aos professores e professoras, reconhecimento de seus direitos políticos, reforma das Universidades"(LUQUE, 2011, p. 693).

No começo do novo governo Adeco (como são conhecidos os partidários da Ação Democrática), foram amplamente divulgadas as teses do Estado Docente, do Humanismo Democrático e da Escola Unificada - proposta para uma instituição integrada do maternal ao ensino superior. Ganhou força nessa década de 1940 o movimento que fundou as Escolas Experimentais e as Repúblicas Escolares, processos autogestionados com participação de pais e estudantes. Além de um processo de Constituinte, foram realizadas as três primeiras campanhas de alfabetização no país; cursos de formação para professores e profissionais da educação, que tinham agora melhores salários; foi criada a primeira fábrica-escola nacional e oferecidos diversos cursos técnicos no interior do país; aprovado decreto que unificava critérios de avaliação e elaborado um novo projeto de Ley Orgánica de Educación (LUQUE, 2011, pp. 696-700), que em menos de quarenta dias de promulgada, foi derrocada junto com Rómulo Gallegos por outro golpe militar.

\section{De volta ao militarismo (1948) com Pérez Jimenez (1952)}

Os primeiros anos de militarismo não viram grandes mudanças na área educacional. Foram dois governos com aproximadamente dois anos cada um: Carlos Delgado Chalbaud e Germán Suárez Flamerich, assumindo este último como Presidente Encarregado depois do assassinato do primeiro. Em dezembro de 1952, Pérez Jiménez assume como Presidente Encarregado da Junta Militar golpista e é "eleito" no ano seguinte. A primeira medida educacional de Pérez Jimenez foi a ruptura com a tese de Estado Docente e a perseguição seletiva dos líderes do movimento educacional que se organizava desde 1940. Yolanda Ramírez explica como a educação começou a discutir e se adequar a um planejamento nacional vinculado ao desenvolvimento industrial do país, ou seja, necessidade de mão de obra qualificada para "o trabalho útil. Fica a suspicácia no significado de utilidade em tempos de ditadura" (SULBARÁN, 2011, p. 39-41, p 42). Assim, a pedagogia nas escolas foi se orientando mais por teorias condutivistas e do saber atomizado, valendo-se da Pedagogia por Objetivos. Ainda que existisse uma preocupação com o desenvolvimento no interior do país, 


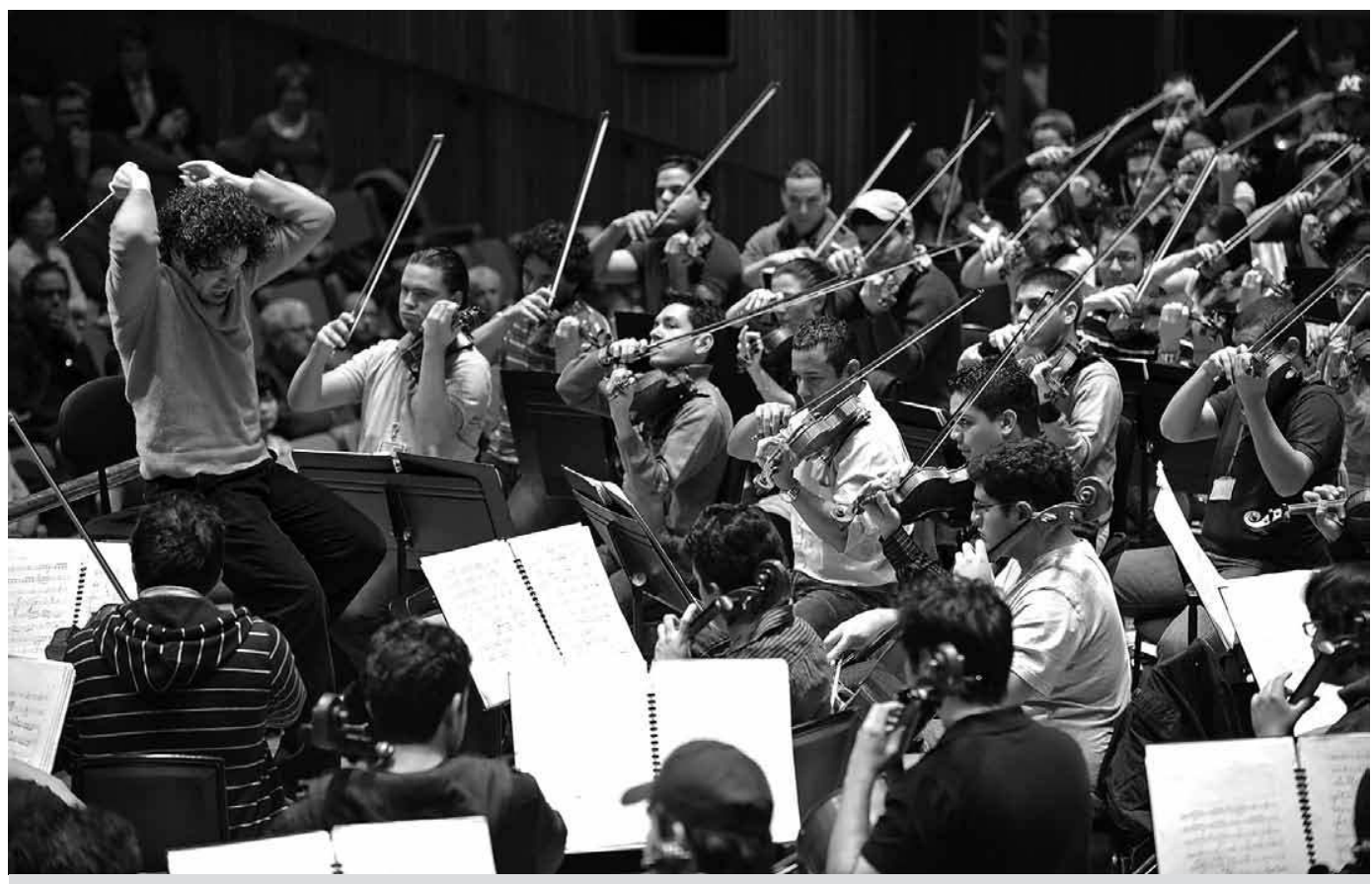

Educação musical na Venezuela (Fonte: http://www.publico.pt)

refletida na expansão a áreas antes desatendidas, a ditadura "promove a privatização e contribui com a deterioração" (SULBARÁN, 2011, p. 44) da educação (Tabela 1), enquanto estimulou o desenvolvimento da Igreja na educação (MANTEROLA e CÓRDOVA, 2011, pp. 93-95). Esses foram os traços gerais até 1958, quando a "democracia” volta através do Golpe de Estado de 1958.

\section{Voltam Rómulo Betancourt e AD (1959-69)}

O retorno dos Adecos ao poder representava o resgate da democracia e, para a educação, democratização de acesso. Impulsionada pelo acordo de universalização da educação básica assumido junto à ONU em 1956, a social-democracia se dedicou à palavra de ordem Educación para todos. O governo de Betancourt, com o maior crescimento de matrícula da história venezuelana até então (53\%, Tabela 1), deu início a uma série de medidas que seu sucessor Raúl Leoni daria apenas continuidade mais amena, com o adicional de, em 1966, decretar normativa para elaboração, avaliação e distribuição gratuita de material didático (SULBARÁN, 2011, p. 49). O governo federal priorizou colocar as crianças na escola, inclusive da classe trabalhadora, porém descuidou de sua qualidade, chegando a decretar salas com 50 alunos nas instituições públicas. Principalmente no governo Leoni, foi descarada a defasagem entre o aumento no número de estudantes $(19,2 \%)$ e a construção de novas instalações $(-3 \%)$ (SULBARÁN, 2011, p. 47).

Para ilustrar o descaso com a formação docente, vale destacar que um estudo oficial realizado em 1968 identificou que 79\% dos professores venezuelanos do ciclo secundário haviam feito estágio nos EUA ou Porto Rico (MANTEROLA e CÓRDOVA, s/d, p. 108). A Igreja também cresceu, principalmente para formação técnica dos 'pobres', através de acordos com o governo (MANTEROLA e CÓRDOVA, 2011, p. 114). 
Rumo à reforma de 1969, com maior número de matrículas e uma formação docente que não tinha como acompanhar o ritmo, os professores tenderam a enfatizar indicadores, dedicando-se mais a um acompanhamento global do corpo discente (RAMÍREZ, 2011, pp. 510-517). Já no final do governo Leoni, a 'popular' AD aumentou a repressão a movimentos sociais devido a antagonismos dentro da aliança partidária das classes dominantes, provavelmente acirrados pelas tentativas de golpe civil-militar em 1962: o Carupanazo (04/05/1962) e o Porteñazo (02/06/1962).

\section{Agora é a vez da democracia-cristã, COPEI (1969-74)}

Pela primeira vez na história da República venezuelana, um partido passou a presidência ao seu opositor pacificamente em 1969. Agora com a estabilidade democrática propiciada pelo notório Pacto de Punto Fijo de 1958, era necessário se dedicar à qualidade nas escolas: é decretada mais uma Reforma na Educação. A ideologia social-cristã se dedicou mais ao ensino secundário e superior para dar respostas à classe dominante que exigia "a adequação do sistema escolar ao sistema produtivo" (SULBARÁN, 2011, p. 51). Acontecimentos internacionais - como o conflito no Oriente Médio, a Revolução Cubana e a Guerra do Vietnã - impulsionaram o modelo desenvolvimentista que ganhava força desde o começo da década. Com o produtivismo ganhando espaço, a rígida e pesada estrutura vigente de trabalho não contribuía com a educação. Ramírez explica como as disciplinas instrumentais ganharam principal destaque, dominando na época um ensino de caráter repetitivo e reprodutivo. Foi também criado um novo regime de educação para adultos. Os professores entraram em greve pela primeira vez e conseguiram acordo coletivo intermediado pelo Congresso (MANTEROLA e CÓRDOVA, 2011, p. 111).

\section{Carlos Andres Pérez na Venezuela Saudita (1974-79)}

O Yom Kipur foi um elemento conjuntural especialmente significativo para a economia nacional em 1973, que lançou o preço do petróleo de dois para 14 dólares. O país manteve um crescimento médio de $8 \%$ ao ano no período de Carlos Andrés Pérez (CAP), que contraditoriamente deixou a presidência com uma dívida externa dez vezes maior que a de 1974 . Não foram realizadas grandes obras no setor educativo, apesar de se observar nesse período a segunda maior taxa de crescimento da matrícula da história democrática do país (Tabela 1). A isso, o governo deu nome de Revolução na Educação, mas as medidas seguiam na mesma linha reformista do governo anterior. Em relação à pedagogia e ao planejamento escolar, foi nesse momento instituída a Escola Unificada, antigo sonho da educação venezuelana que permite a continuidade entre ensino básico, secundário e superior e dá flexibilidade para o estudante mudar do ciclo regular ao diversificado (técnico) durante o ensino médio.

Em 1975, as críticas à educação eram evidentes: "orientação memorística, desvinculação com a realidade, carências de estímulo para a criatividade, sobrecarga de áreas e disciplinas" (RAMÍREZ, 2011, p. 523). Apesar disso e do rombo orçamentário, CAP foi reconhecido internacionalmente e eleito vice-presidente da Internacional Socialista em 1976. 


\section{A década perdida de 1980 com COPEI-AD (1979-89)}

Ambos os governos de Luis Herrera Campins (COPEI) e Jaime Lusinchi (AD) não alteraram muito o panorama da educação. As taxas de matrícula mantiveram um crescimento similar em ambos os períodos (Tabela 1) e começou a se refletir também no setor privado a tendência à superlotação, à qual o governo adeco respondeu dobrando a quantidade de instalações privadas de educação (SULBARÁN, 2011, p. 83) em apenas cinco anos. Economicamente, o setor empresarial parasitário cresceu e se fortaleceu, esfriando um pouco o paradigma industrial desenvolvimentista e seu reflexo sobre a educação e, ao mesmo tempo, reforçando a identidade de classe dos criollos com a burguesia internacional e seu estilo de vida.

O país assinou no final da década de 1970 convênios internacionais com membros da UNESCO que tiveram implicação prática direta nas escolas venezuelanas, como a definitiva institucionalização da Educação básica e definição dos ciclos básico e médio. Ao mesmo tempo no âmbito pedagógico, também por influência das ideias de Piaget, começa a concepção de educação por ciclos, cobrando atenção ao desenvolvimento pessoal do estudante. Na revisão da reforma de 1980, foram retomados alguns conceitos da Escola Nova plasmados na reforma de 1969, como eixos de interesse e pedagogia de projetos vinculados à comunidade, e foi dada especial atenção ao aprendizado fora dos espaços de encontro docente-discente (RAMÍREZ, 2011, p. 533), incluindo à necessidade de tempo para planejamento.

O governo copeiano (1979-84) trouxe consigo a ideia de valorização do trabalho, de convencer os jovens que o trabalho "é um fator de humanização e melhoria" (MANTEROLA e CÓRDOVA, 2011, p. 115) e promoveu o Seminário de Identidade Nacional para o setor educativo. Segundo Ramírez (2011, pp.499-537), muitas das propostas da reforma de 1969 que foram antes deixadas de lado, como o aprendizado por descoberta e por processos, entraram em vigor em 1985. Já o governo adeco (1984-89) começou seu quinquênio paralisando todas as iniciativas do antecessor, mantendo algumas das iniciativas da Escola Nova e engavetando outras. Assim, houve avanços e retrocessos, mas as decisões eram mais voltadas a aspectos político-partidários que pedagógicos.

A fraseologia ideológica e o jogo politiqueiro são apenas reflexos de uma década que parece regredir a condições mais críticas que as de 1970. O preço internacional do petróleo voltou a cair, a dívida externa pesou ainda mais e a desvalorização do bolívar foi inevitável dentro do neoliberalismo copeiano, conjugando o Viernes Negro de 1983, prelúdio do que estaria por vir em 1989. Iradia Sulbarán o sintetiza:

"A crise que já despontava desde a década de 70, aprofundava-se. A recessão econômica conjugada com o clientelismo partidário, a corrupção e a crescente incapacidade do estado de proporcionar uma base adequada de serviços sociais (educação, saúde, seguridade social), constituiam sinais de que a crise não era apenas econômica, mas social". (SULBARÁN, 2011, p. 60).

\section{A volta de CAP, o filho pródigo (1989-93)}

CAP chegou a um país socialmente desolado, politicamente degenerado e economicamente destruído: $83 \%$ da população vivia sem infraestrutura básica e $70 \%$ estavam em condições de subnutrição (CÉLULA, 2009, 00:29:35, 00:13:00 ). Muitos 
analistas consideram que sua vitória nas urnas refletiu a esperança popular de melhores dias, devido à lembrança de sua gestão anterior, em um momento de "esgotamento político do bipartidarismo tradicional” (SULBARÁN, 2011, p. 70).

No âmbito educacional, foi aprovada lei que normatiza a estrutura do ensino médio técnico e profissional. O aumento drástico da matrícula no setor privado (Tabela 1) foi produto de uma pequena melhora no preço do petróleo e dos critérios neoliberais de investimento. Para além disso, não se viu muitos avanços, o panorama nacional estava dominado por outros eventos.

No primeiro mês de mandato, CAP trouxe para o país o famigerado pacotazo neoliberal que todos latino-americanos tiveram o desprazer de conhecer. Porém, o povo venezuelano decidiu não admitir ver seu salário reduzido a três quilos de tomate, como no Viernes Negro, enquanto assistia na televisão os jantares de gala entre as belas misses venezuelanas e seus futuros maridos da alta burguesia. As imagens da época demonstram claramente o caráter de classe e as motivações daqueles que estavam nas ruas: "Sempre as medidas econômicas afetam o povo, nunca afetam a parte aristocrática!” (CÉLULA, 2009, 00:29:35, 00:06:10).

Como reza a cartilha, e um bom católico neoliberal não pode deixar de cumprir com suas orações, o trator da repressão fez seu trabalho de terraplanagem, mas o país já não era o mesmo. A partir de 1989, a "Venezuela se transformou em uma sociedade de protesto e rebeldia, onde os eventos de protesto social se duplicaram em relação aos acontecimentos entre 1958 e 70" (MANTEROLA e CÓRDOVA, 2011, pp.119120). Principalmente por esse motivo, não foram introduzidas mudanças na educação durante o segundo governo de CAP, "salvo as medidas compensatórias introduzidas mediante o conjunto de programas sociais que tinham uma incidência direta sobre a população escolar" (SULBARÁN, 2011, p. 71). No nível estadual, a primeira eleição direta para governadores em 1989 colocou personagens mais populares no poder e trouxe novas e interessantes iniciativas no âmbito educacional, "onde se realizam verdadeiras mudanças pedagógicas, tanto no nível didático como estrutural nas escolas" (MANTEROLA e CORDOVA, 2011, p. 119), principalmente para "atender a população escolar de baixos recursos [...] da educação básica” (SULBARÁN, 2011, p. 79). Mas suas implicações se restringiam à esfera regional.

O país estava, portanto, em convulsão. A situação se intensificou com as duas tentativas de golpe de estado em 1992. Eis que, do episódio de 04 de fevereiro, surge um personagem que realizou duas coisas com as quais os venezuelanos se identificaram: 1) Entrar com um tanque no Palácio de Miraflores, arriscando a vida para enfrentar os políticos identificados como inimigos do povo; 2) Assumir toda responsabilidade pelo que aconteceu, algo que nenhum político venezuelano havia feito até então. $O$ jovem Chávez personificou assim a esperança de mudança. No outro lado do espectro, em 1993, o Congresso destituiu CAP do poder por malversação comprovada de fundos.

As manifestações foram tomando as ruas com cada vez mais frequência, e os trabalhadores da educação não estavam fora disso. Pablo Imen cita, por exemplo, que "a Frente de Educadores se conformou com o apoio do movimento pedagógico pré-existente, que se desenvolveu desde final dos anos oitenta e cresceu exponencialmente a partir das eleições presidenciais de 1998" (IMEN, 2011, p.396). O país assistiu algumas mudanças significativas, não a partir do governo, mas da população. 


\section{Rafael Caldera volta com outra reforma (1994-1999)}

Diversos diagnósticos acumulados desde a década de 1970 apontavam a deterioração da educação venezuelana. O momento histórico pedia mudanças e a "Reforma Educacional” proposta por Rafael Caldera propunha certos elementos inovadores como:

(...) a escola como centro de ação para a transformação e promoção do desenvolvimento integral do aluno, assumir a concepção construtivista, incorporar a transversalidade, propor a metodologia de projetos, organizar o conhecimento por tipo de conteúdo e assumir o enfoque qualitativo de avaliação (SULBARÁN, 2011, p. 73).

Porém, Albornoz indica que a reforma não produziu mudanças significativas porque "enfocou todo seu empenho no nível da escolaridade e não da educação" (ALBORNOZ, 1999, p. 28). Houve uma importante iniciativa de descentralização financeira, repassando aos estados parte do orçamento educativo e implementando os Programas de Alimentação Escolar (PAE) e de Promoção da Educação Oficial, cujo enfoque era a melhora da qualidade. Talvez esse investimento na educação pública explique a redução de 11,6\% na matrícula privada que pode se observar no período (Tabela 1). Assim, já em 1997, o aspecto pedagógico voltou a ter importância, a pedagogia por projetos voltou a ganhar espaço e os eixos estratégicos voltaram a incorporar valores, não apenas conteúdos. Aqui apareceu pela primeira vez a palavra 'competências' para avaliação estudantil.

\section{Viłória Bolivariana nas eleições (1998)}

Chegou a chamada Revolução Bolivariana à Venezuela, um país destruído pelo neoliberalismo, cansado de trabalhar pelos interesses internacionais, mas com um povo esperançoso e disposto a reconstruir sua história.

Como primeiras medidas, o governo decidiu dar continuidade à reforma de Caldera, convocou esse povo a participar da Constituinte e dos debates sobre o Plano Nacional de Educação (PNE) e deu início ao plano piloto das Escolas Bolivarianas, considerado projeto bandeira para o Sistema Educacional Bolivariano $(S E B)$ e futuras políticas educacionais do governo. Muitos analistas consideram este um ponto de viragem, argumentam que o PNE e as Escolas Bolivarianas mudaram os conceitos de educação até então, e que "representam um novo modelo de atenção integral" (SULBARÁN, 2011, p. 78).

Sobre a Constituinte de 1999, Ramírez discorda ao afirmar que até 2001 "nada novo em assuntos pedagógicos tinha acontecido na Escola Básica” (RAMíREZ, 2011, p. 538), mas que ela serviu para dar primeiros passos de "transcendental importância" ,já que implementou a "jornada escolar completa, garantiu o transporte, cantina, calçado, uniformes, serviço médico assistencial e começou a melhoria da infraestrutura dessas escolas". Ramírez afirmou em 2001 que as propostas do PNE de 1999 apenas resgatavam, em grande parte, o que tinha sido proposto em 1997 que, por sua vez, resgatava os antigos ideais da Escola Nova. Com uma exceção, "o que era realmente inovador consistia no vínculo da escola com a vida comunitária e os meios de comunicação social" (RAMÍREZ, 2011, p. 539). A Escola Comunitária, como centro da atividade comunitária, como parte integrante do poder popular, mudou de significado. 


\section{A modo de conclusáo}

Depois de tantos percalços pela história política da Venezuela no século XX, vemos como as políticas educacionais acompanham e estão condicionadas pelos paradigmas e interesses da fração da classe dominante que ocupa o governo vigente. Pode-se observar também que a melhoria na educação dos últimos anos se sustenta sobre a base de um processo de mudança qualitativamente diferente dos períodos anteriores, do contrário, não seriam possíveis melhorias tão significativas sobre uma estrutura social, política e econômica completamente destruída. Esse artigo pretendeu demonstrar como a conjuntura econômica internacional e política nacional exerceram influência direta sobre a educação venezuelana nos anos prévios à chegada de Chávez ao poder. A Educação durante a Revolução Bolivariana merece um estudo próprio, que considera os fatores econômicos objetivos, assim como os políticos e culturais subjetivos que a movem. Esperamos com o presente trabalho contribuir para esse estudo tão necessário.

\section{Referências Bibliográficas}

ALBORNOZ, Orlando. Del Fraude a la Estafa, La Educación en Venezuela: Las políticas educativas en el segundo quinquenio presidencial de Rafal Caldera (1994-1999). Caracas: Ediciones de la Facultad de Ciencias Económicas y Sociales de la UCV.1999. ASSADOURIAN, Carlos S.; CARDOSO, Ciro Flamarion S.; CIAFARDINI, Horacio; GARAVAGLIA, Juan Carlos; LACLAU, Ernesto. Modos de producción en America Latina. Coleção Cuadernos del pasado y presente n.40. Ed. 11. Siglo XXI Editores: Ciudad de México. 1986.

CÉLULA, Cooperativa Audiovisual. 27-F 1989 La Rebelión del Pueblo. Documentário. Produção de La Célula e Venezolana de Televisión. Direção de José Gaya e Gerby Reyna. Vídeo documentário. 00:29:35. Disponível em http://www.dailymotion.com/ LACELULA\#video=xaxur6. Última visita em 15/05/2014.

FIGUEROA, Luis Brito. Historia Económica y Social de Venezuela: una estructura para su estudio. Tomo I. Caracas: Ediciones de la Biblioteca de la universidad Central de Venezuela, 1975.

IMEN, Pablo A. Pedagogía y emancipaciones en la Venezuela bolivariana: la política educativa para el socialismo del siglo Xxi. Educação E̊ Sociedade. Centro de Estudos Educação e Sociedade. Universidade Estadual de Campinas, v. 32, n. 115, p. 393-410, abr.-jun. 2011. Disponível em http://www.cedes.unicamp.br/revista/rev/rev115.htm. Úlitima visita em 15/05/2014.

LÓPEZ SÁNCHEZ, Roberto. El protagonismo popular en la historia de Venezuela. Facultad Experimental de Ciencias. Universidad del Zulia: Maracaibo, 2002.

LUQUE, Guillermo. Luis Beltrán Prieto Figueroa: Educador de Pueblos y Combatiente Socialista. In: (comp). Venezuela: Medio siglo de historia educativa 1951-2001: Descripción y análisis del Sistema Escolar Venezolano y sus Modalidades. Caracas: Ministerio del Poder Popular para la Educación Universitaria e Centro Internacional Miranda, 2011. p.666-736

MANTEROLA, Carlos; CÓRDOVA, Doris. La Educación Secundaria en Venezuela: Período 1951-2001. In:___ (comp). Venezuela: Medio siglo de historia educativa 1951-2001: Descripción y análisis del Sistema Escolar Venezolano y sus Modalida- 
des. Caracas: Ministerio del Poder Popular para la Educación Universitaria e Centro Internacional Miranda, 2011. p.93-125.

MASTRONALDI, Nancy; BLANCO, Andreina. Censo 2011: Venezuela tiene 28.946.101 habitantes. Sessão Nacional da versão digital do Jornal Correo del Orinoco, 09/08/2012. Disponível em http://www.correodelorinoco.gob.ve/tema-dia/ censo-2011-venezuela-tiene-28-946-101-habitantes/. Última visita em 15/05/2014. RAMÍREZ, Yolanda. Una mirada pedagógica a las Reformas Educacionales en Venezuela 1951-2001. In: LUQUE, Guillermo (comp). Venezuela: Medio siglo de historia educativa 1951-2001: Descripción y análisis del Sistema Escolar Venezolano y sus Modalidades. Caracas: Ministerio del Poder Popular para la Educación Universitaria e Centro Internacional Miranda, 2011. p.499-537.

RANGEL, Domingo A. La oligarquia del dinero. Tomo III de 'Capital y Desarrollo'. Caracas: Editorial Fuentes. 1971.

RIVAS, Pedro J. Educación bolivariana: entre la utopía realizable y no hacer nada. Educere, Meridad, v. 11, n. 36, março, 2007. Disponível em: <http://www.scielo.org. ve/scielo.phpscript=sci_arttext\&pid=S1316-49102007000100011\&lng=es\&nrm=i so>. Última visita em 15/05/2014.

SANTOS, Oder José dos. Reestruturação Capitalista: Educação e escola. Trabalho e Educação, Belo Horizonte, NETE/FaE/UFMG, v.13, n.1, p.79-89, jan./jul. 2004. SEGRERA, Francisco López. Tendencias Mundiales y Regionales de la Educación Superior, Crisis Económica Mundial e Innovación. Material do Curso Internacionalização da Educação Superior da REGGEN/Rede e Cátedra da UNESCO em Economia Global e Desenvolvimento Sustentável da Faculdade de Educação da Universidade Federal do Ceará. Fortaleza: Subsede Sudeste da REGGEN. 20 de agosto de 2013. Disponível em http://www.seminarioreggen.ufc.br/curso/arquivos/8_TEMA1a_TENDENCIAS.pdf. Última visita em 15/05/2014.

SULBARÁN, Iraida. La Educación Primaria en Venezuela: Una mirada hacia la historia (1951-2001).In: (comp). Venezuela: Medio siglo de historia educativa 1951-2001: Descripción y análisis del Sistema Escolar Venezolano y sus Modalidades. Caracas: Ministerio del Poder Popular para la Educación Universitaria e Centro Internacional Miranda, 2011. p.39-91.

UIS. UNESCO Institute of Statistics. UIS Statistics in Brief: Education (all levels) profile - Venezuela (Bolivarian Republic of). Montreal, Canadá: UIS, 2013. Disponível em http://stats.uis.unesco.org/unesco/TableViewer/document.aspx?ReportId=198. Última visita em 15/05/2014.

UNESCO. The State of Education in Latina America and the Caribbean: Towards a Quality Education for All - 2015. OREALC/UNESCO, Santiago, Chile: 2013. Disponível em http://www.orealc.cl/educacionpost2015/wp-content/blogs.dir/19/ files_mf/efainformefinaldef57.pdf. Última visita em 15/05/2014.

WIKIPEDIA, A enciclopédia livre. Golpes de Estado na Venezuela. 31 de março, 2013. Disponível em http://es.wikipedia.org/wiki/Presidente_de_Venezuela.Última visita em 15/05/2014.

ZUCK, Débora V. NOGUEIRA, Francis M. G. A Concep̧̧ão de Educação Escolar Bolivariana da Venezuela: Proyecto Simoncito, Escuela Bolivariana e Liceo Bolivariano e os Avanços nos 10 Anos do Governo Bolivariano. Trabalho apresentado nas Jornadas Bolivarianas de 2009, evento anual do Instituto de Estudos Latino-americanos da Universidade Federal de Santa Catarina. 2009. Disponível em http://www.iela. 
CIÊNCIA \& LUTA de CLASSES DIGITAL

ufsc.br/cd2009/artigos/JornadasBolivarianas_concepcao_de_educacao_escolar.pdf. Última visita em 15/05/2014. 